\title{
ADMINISTRAÇÃO E GESTÃO DE DESENVOLVIMENTO DO ATLÂNTICO NORTE NO GOVERNO DO BRASIL: UMA ANÁLISE HISTÓRICA DO BANCO MUNDIAL
}

\section{Bill Cooke ${ }^{1}$}

\section{Resumo}

Este artigo discute a existência de uma forma particular de gerencialismo 'SWIMMING', Administração e gestão do Desenvolvimento no Norte Atlântico ('North Atlantic Development Administration and Management' sigla em Inglês - NADAM - acrônimo em Inglês - SWIMMING). A análise empírica de documentos de projetos do Banco Mundial, a partir de 2009, fornece aos atores do Atlântico Norte, como o Banco Mundial, os privilégios de representação, inclusão e exclusão da SWIMMING. A análise revela como SWIMMING exige atores brasileiros a serem representados como suplicantes e merecedores, usando termos como "diligente" e "firme" para legitimar os beneficiários dos empréstimos do Banco Mundial. Ele também revela como os projetos são gerenciados para contornar e substituir as possibilidades de mudança democrática através de meios constitucionais, como as eleições. Tal mudança é apresentada nos documentos de gestão dos projetos como um "risco", com os atores político-partidários apresentados como tecnocratas neutros na implantação de técnicas de gestão "objetivas", quando na realidade eles sustentam uma mudança para a ideologia neoliberal. Também surpreendente é a ausência da pesquisa brasileira especializada - de estudiosos individuais, ou como consubstanciada na rica literatura peerreviewed brasileira em administração pública e de gestão. $\mathrm{O}$ artigo conclui situando o gerencialismo do SWIMMING na longa tradição de intervenção imperial do Atlântico Norte no Brasil, enquanto um prérequisito de que a tomada do poder discursivo e do silenciamento do conhecimento local, satisfaz as exigências da "ciência" do Atlântico Norte.

Palavras-chaves: Gestão Internacional, Banco Mundial, Neo-colonialismo, Gestão de Projetos.

\footnotetext{
${ }^{1}$ The York Management School - University of York - Freboys Lane - Hestlington - York - Reino Unido.

E-mail: bill.cooke@york.ac.uk
} 


\title{
NORTH ATLANTIC DEVELOPMENT ADMINISTRATION AND MANAGEMENT IN THE GOVERNANCE OF BRAZIL: A HISTORICAL ANALYSIS OF THE WORLD BANK
}

\begin{abstract}
This article proposes the existence of a particular form of managerialism 'NADAM', North Atlantic Development Administration and Management. The privileges of representation, inclusion and exclusion NADAM provides North Atlantic actors like the World Bank are examined empirically through World Bank project documents from 2009. The analysis reveals how NADAM requires Brazilian actors to be represented as supplicant and deserving, using terms such as 'diligent' and 'steadfast' to legitimize the beneficiaries of World Bank loans. It also reveals how projects are managed to bypass and override the possibilities of democratic change through constitutional means of elections. Such change is presented in project management documents as a 'risk', with politically partisan actors presented as neutral technocrats deploying 'objective' management techniques, when in reality they sustain a neoliberal change ideology. Also startling is the absence of Brazilian research expertise - of individual scholars, or as embodied in the rich Brazilian peer-reviewed literature on public sector administration and management. The article concludes by situating the managerialism of NADAM in the long tradition of North Atlantic imperial intervention in Brazil, a pre-requisite of which is the assumption of discursive power and the silencing of local knowledge, even that which meets the requirements of North Atlantic 'science'.
\end{abstract}

Keywords: International Management, World Bank, Neo-colonialism, Project Management.

\section{ADMINISTRACIÓN Y LA GERENCIA DE DESARROLLO DEL ATLÁNTICO NORTE EN EL GOBIERNO DE BRASIL: UN ANÁLISIS HISTÓRICO DEL BANCO MUNDIAL}

\section{Resumen}

En este artículo se analiza la existencia de una forma particular de gerencialismo - "SWIMMING", Gerencia de Administración y Desarrollo en el Atlántico Norte ('North Atlantic Development Administration and Management' - 'Administración del Atlántico Norte Desarrollo y Gestión' NADAM, anacrónico en Inglés - 'SWIMMING'). El análisis empírico de los 


\section{ADMINISTRAÇÃO E GESTÃO DE DESENVOLVIMENTO DO ATLÂNTICO NORTE NO GOVERNO DO BRASIL: UMA ANÁLISE HISTÓRICA DO BANCO MUNDIAL \\ Bill Cooke}

documentos del proyecto del Banco Mundial de 2009, da a los actores del Atlántico Norte, como el Banco Mundial, el privilegio de representación, la inclusión y la exclusión de la 'SWIMMING'. El análisis revela cómo 'SWIMMING' requiere actores brasileños para ser representadas como un suplicante y merecedor, utilizando términos como "diligente" y "firme" a los beneficiarios legítimos de los préstamos del Banco Mundial. También revela cómo se gestionan los proyectos para eludir y sustituir las posibilidades del cambio democrático a través de medios constitucionales como las elecciones. Este cambio se muestra en los documentos de gestión de proyectos como un "riesgo", con los actores políticos partidistas presentan como tecnócratas neutrales en la aplicación de técnicas de gestión "objetiva" cuando en realidad que apoyan un cambio a la ideología neoliberal. También es sorprendente la ausencia de investigación brasileña especializada - de académicos individuales, o que se concreta en la rica literatura revisada por pares de Brasil en la administración y gestión pública. El artículo concluye colocando el gerencialismo de 'SWIMMING' en el largo tradición imperial de intervención del Atlántico Norte en Brasil, como requisito previo que la toma del poder discursivo y el silenciamiento de conocimiento local cumple los requisitos de la "ciencia" del Atlántico Norte.

Palabras-clave: Gestión Internacional, Banco Mundial, Neocolonialismo,

Gestión de Proyectos.

\section{Introdução}

Em 1997, Diana Wong-MingJi e Ali Mir escreveram um capítulo de livro intitulado "quão internacional é a gestão internacional [GI]". Nele, eles examinaram cada artigo publicado nos principais periódicos de gestão e tabularam as origens da pesquisa (por afiliação institucional dos autores) e os países sobre os quais a pesquisa se tratava. Contrariamente, os autores também tabularam aqueles países que, por afiliação dos autores, não tinham contribuído para a literatura de Gestão Internacional (GI) e que não foram representados como tópicos de pesquisa. Por fim, os autores concluíram que a pesquisa "é predominantemente conduzida por acadêmicos dos Estados Unidos e por um número reduzido de países da Europa ocidental.... que a pesquisa em GI foca em conceitos gerais e desterritorializados ou em problemas relacionados aos Estados Unidos, Europa Ocidental e Japão; [e] que a pesquisa em GI se baseia inteiramente por fontes publicadas nos Estados Unidos" (1997, p. 360). Em outras palavras, GI, como representada na principal literatura de gestão, exclui os diversificadamente nomeados Terceiro Mundo, Sulistas, e/ou Países em 


\section{ADMINISTRAÇÃO E GESTÃO DE DESENVOLVIMENTO DO ATLÂNTICO NORTE NO GOVERNO DO BRASIL: UMA ANÁLISE HISTÓRICA DO BANCO MUNDIAL \\ Bill Cooke}

Desenvolvimento (ver também JACK et al., 2008). Tais status de países Terceiro Mundo, Sulistas, ou em Desenvolvimento - são construídos e sustentados pelo ato de exclusão no exercício de poder geopolítico do conhecimento. Desde 1997, era de se esperar que estudiosos de todas as partes propusessem outras nomenclaturas. Não menos importante, colegas Brasileiros têm levantado seus perfis nos fóruns acadêmicos do Atlântico Norte, como a Academia de Administração dos Estados Unidos (sigla em inglês - USAM - US Academy of Management). Entretanto, como Nkomo (2009) e Murphy e Zhu (2012) evidenciam, embora possa haver um crescente aumento de contribuições das margens, os estudos acadêmicos em gestão internacional são, empiricamente, um Império Norte Americano.

Simultaneamente, como já ressaltei em outros textos (por exemplo em Cooke 2003, 2004), existe um tipo de gestão internacional que é endossado em diferentes instituições do Primeiro Mundo, mas que tomam o chamado Mundo em Desenvolvimento como seu principal foco. Isto é, há uma disciplina sobre gestão em diferentes países do mundo, com o nome 'gestão' no título, com seus próprios praticantes e práticas e literatura de pesquisa. Institucionalmente, isso é ensinado na graduação de prestigiosas universidades do Primeiro Mundo, mas comumente isso não ocorre em suas escolas de negócios (ver COOKE, 2004); como em Harvard na Escola de Governo John F. Kennedy, por exemplo. Esta disciplina já foi chamada de "Administração do Desenvolvimento" e é agora mais comumente chamada de Gestão do Desenvolvimento. A inclusão de algumas nações nessa categoria diferenciada, de pouca relação com a modernidade, é também um exercício do poder geopolítico do conhecimento do Atlântico Norte.

Para o Brasil, isso é duplamente irônico e duplamente ultrajante dado que o Brasil tem sua própria tradição em 'gestão do desenvolvimento', cuja origem pode ser vista nos movimentos Modernistas do começo do século XX, no Estado Novo de Getúlio Vargas e seu sucessor, nos seguidores do Brasil da doutrina CEPAL e no estabelecimento de instituições como o Banco Nacional de Desenvolvimento Econômico e Social - BNDES (COOKE; FARIA, 2013; MOTTA; SCHMITT, 2013). Sendo este o caso, a autoterminologia universal e deslocalizada de 'Administração do Desenvolvimento' ou 'Gestão do Desenvolvimento' não é mais aceita, já que ela mascara a direção do sujeito-objeto e a geopolítica do seu lócus de enunciação. Mais apropriado é o termo que utilizo aqui 'Administração e Gestão do Desenvolvimento do Atlântico Norte' ('North Atlantic Development Administration and Management' - sigla em Inglês - NADAM - acrônimo em Inglês - SWIMMING).

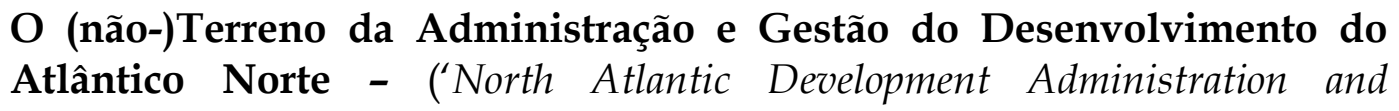




\section{ADMINISTRAÇÃO E GESTÃO DE DESENVOLVIMENTO DO ATLÂNTICO NORTE NO GOVERNO DO BRASIL: UMA ANÁLISE HISTÓRICA DO BANCO MUNDIAL \\ Bill Cooke}

Management' - sigla em Inglês - NADAM - acrônimo em Inglês SWIMMING)

Em outros textos (e.g. em COOKE, 2004), meu ponto de partida sobre a natureza da gestão de desenvolvimento (agora NADAM) é o trabalho de Alan Thomas (1996, ver também 2007), que deu ao termo três possíveis significados. O primeiro foi gestão em um processo de desenvolvimento econômico em andamento ou gestão durante esse processo. Pode-se argumentar que, por definição, todos os processos gerenciais que estão situados dentro de um processo mais vasto de modernização social e econômica são gestão de desenvolvimento, e assim esse significado não é tão útil ou amplamente aceito. O segundo significado de Thomas foi o de gestão nos chamados países em desenvolvimento. Este significado é, para Thomas, muito simples, o qual estou de acordo, já que obscurece a essência do SWIMMING.

Assim, para Thomas (1996, p. 108), o significado mais apropriado é, parafraseando-o, "a gestão deliberada de intervenções de desenvolvimento". Este é, arquetipicamente e atualmente, o caminho pelo qual organizações multilaterais e bilaterais - mais frequentemente Organizações Não governamentais (ONGs) como a Oxfam, o Fundo "Save the Children", as organizações internacionais como o Banco Mundial ou o Programa das Nações Unidas para o Desenvolvimento (PNUD), as agências estatais como o Departamento de Desenvolvimento Internacional do Reino Unido (DFID) ou a Agência de Cooperação Internacional do Japão - usam processos e práticas de gestão em seu trabalho de desenvolvimento em países diferentes daqueles onde estão sediadas, e usam também em si mesmas como organizações. Minha finalidade aqui não é desfazer as relações institucionais entre essas agências, seus governos e aqueles do Brasil. Ao invés disso, como acadêmico crítico de gestão, é explorar como usos particulares de gerencialismo dentro da gestão do NADAM mantém e perpetua relações particulares de poder.

Este é, concordo, um elemento substancial de como o NADAM se representa. Entretanto, Brinkerhoff (2008) aponta para outra dimensão mais forte e constante do NADAM a qual Thomas minimiza. Além de ser um processo (de gestão de intervenções de desenvolvimento internacional), o NADAM é o fim e o meio. Algumas intervenções do NADAM buscam aprimorar a gestão em si arquetipicamente no domínio público do chamado "país em desenvolvimento". Isso data dos tempos antigos da administração do desenvolvimento como "aplicação prática da teoria de modernização" (TURNER; HULME, 1997, p. 12). Tais intervenções frequentemente invocam discursos gerencialistas genéricos, como o da Nova Gestão Pública (NPM) ou do Gerenciamento dos Recursos Humanos (HRM), por exemplo, e, a partir da década de 1980, implicitamente adquirem provisões públicas por atores não estatais, 


\section{ADMINISTRAÇÃO E GESTÃO DE DESENVOLVIMENTO DO ATLÂNTICO NORTE NO GOVERNO DO BRASIL: UMA ANÁLISE HISTÓRICA DO BANCO MUNDIAL \\ Bill Cooke}

amplamente pelas corporações e pelas ONGs. Além do processo de gestão de intervenções de desenvolvimento, o NADAM busca gerir o estado e as funções do "país em desenvolvimento".

Por definição, o NADAM generaliza e heterogeneiza o que, em uma terminologia adicional, Brinkerhoff chama de "países pobres" (2008 p. 985). Nós não deveríamos nos surpreender que em discussões gerais houvesse poucas considerações específicas sobre o Brasil, conquanto, como vale salientar, haja uma presença constante no país. Uma exceção histórica é o livro de John C. Honey, Estratégia para o Desenvolvimento da América Latina: Administração Pública, de 1968. Esse texto é um pouco menos genérico (a sua unidade de análise é das Américas do Sul e Central, ao invés do Terceiro Mundo como um todo). No entanto, o que o livro de Honey demonstra é que enquanto escritores tenham talvez restringido a administração do desenvolvimento tacitamente em termos de Ásia e África, as instituições internacionais associadas com administração do desenvolvimento - USAID, as Fundações Ford e Rockefeller e Carnegie, a Organização das Nações Unidas (ONU), o Banco Interamericano de Desenvolvimento (BID) e o Banco Mundial - estavam ativas na América Latina ao longo da década de 1960.

E enquanto a história definitiva da administração do desenvolvimento é aguardada na América Latina, há fragmentos que apontam para a existência de um grupo de acadêmicos norte-americanos particularmente ávidos em enquadrar países em si em termos de administração do desenvolvimento, por exemplo, Graham (1968) sobre o Brasil, em uma análise que se detém, significativamente, em 1964. Há também a coleção editada em 1973, Administração de Desenvolvimento na América Latina Development Administration in Latin America (THURBER; GRAHAM, 1973) que contém artigos sobre a América Latina em geral e, mais especificamente, sobre a Venezuela, a Guatemala, o Chile, o México e o Peru, mas não o Brasil. Essa coleção inclui, substancialmente, artigos apresentados na "Conferência em Administração de Mudanças Revolucionárias na América Latina - The Conference on Administering Revolutionary Change in Latin America" ocorrida em Austin, Texas, juntamente com duas outras conferências das quais uma foi co-organizada pela Fundação Getúlio Vargas (FGV). Isto deveria lembrar os acadêmicos e praticantes atuais do NADAM das históricas e recentes associações com regimes autoritários, violentos e totalitários.

\section{Em direção a uma avaliação crítica do NADAM}

Eu já citei (COOKE, 2003) que o ponto de "desenvolvimento nacional" de Dwivedi e Nef (1982) era um aspecto de contrainsurgência norte-americana, "o qual deveria ser alcançado através do desenvolvimento administrativo" (1982, p. 60). Dwivedi e Nef citaram Fall 


\title{
ADMINISTRAÇÃO E GESTÃO DE DESENVOLVIMENTO DO ATLÂNTICO NORTE NO GOVERNO DO BRASIL: UMA ANÁLISE HISTÓRICA DO BANCO MUNDIAL \\ Bill Cooke
}

(1965, p. 277) ressaltando: “quando um país está sendo subvertido, ele não está sendo derrotado, mas mal-administrado. Subversão é literalmente administração com um sinal de menos". Os autores continuam, com uma referência específica à América Latina:

\begin{abstract}
Sociedades tradicionais tiveram que ser salvas, se não do encanto do comunismo, então pelo menos delas mesmas. Nesse contexto, não é surpreendente encontrar uma relação próxima entre assistência militar de um lado e desenvolvimento técnico e econômico do outro... Modernização administrativa frequentemente se tornou uma tentativa de construir as capacidades das forças de segurança... (DWIVEDI; NEF, 1982, p. 63).
\end{abstract}

Mais tarde, em Cooke (2004), em homenagem a Escobar (1988), argumentei fundamentalmente por um reconhecimento e uma análise crítica do NADAM (como abordo aqui) por aqueles associados com os Estudos Críticos em Administração (ECA). Em seu amplo processo de análise, este artigo segue Cooke (2004). Eu tomo o Banco Mundial como arquétipo e significativo em seu próprio direito como a maior, a mais global e a mais materialmente poderosa das organizações de desenvolvimento multilaterais. Então, partindo do material do Banco Mundial, produzido para suas diversas atividades ao redor do mundo, demonstrei como o uso das técnicas e das metodologias de gestão do Banco - particularmente as abordagens participativas e culturalistas denominadas de "gestão suave" por Thrift (2005) - foram usadas para arquitetar a introdução de um conjunto particular de intervenções econômicas neoliberais, frequentemente em nome da redução da pobreza. Tal como ocorre com o objeto que buscamos criticar, o NADAM, foi algo muito geral ao invés de específico em suas orientações e, de fato, parte do seu ponto de vista foi o de demonstrar como a gestão participativa, supostamente envolvendo atores locais, produziu exatamente os mesmos resultados estratégicos em países tão diversos como Bolívia e Camboja.

Parte da minha crítica do ECA em Cooke (2004) foi a sua vasta ênfase em "organização" como unidade de análise, ao invés de olhar o gerencialismo a partir de domínios mais amplos, por exemplo estados e instituições. Aqui, eu essencialmente sigo o imperativo do ECA ao analisar a documentação do Banco em relação ao seu trabalho gerencial no Brasil em um momento particular da história em um passado recente. O Banco Mundial não é o único ator de desenvolvimento multilateral no Brasil (e, claro, como notado, há o compromisso autônomo do próprio Brasil para o desenvolvimento). No entanto, os montantes de empréstimos ao Brasil indicam-no como um grande ator de importante significado nesse País bem como é ao redor do mundo. 


\title{
ADMINISTRAÇÃO E GESTÃO DE DESENVOLVIMENTO DO ATLÂNTICO NORTE NO GOVERNO DO BRASIL: UMA ANÁLISE HISTÓRICA DO BANCO MUNDIAL \\ Bill Cooke
}

O livro referência de Murphy (2008b) não nomeia e nem trata a gestão do desenvolvimento de forma direta. Pertinentemente, Murphy sugere que a instituição do Banco e a ideologia e a prática do Banco servem para gerar e sustentar uma elite gerencialista global, afirmando:

\begin{abstract}
Gerencialismo é a (não) ideologia da elite contemporânea global. O gerencialismo objetiva despolitizar tomadas de decisão coletivas através da desconstrução de problemas na vida social e na organização em uma série de problemas discretos que podem ser resolvidos apesar da aplicação de conhecimentos técnicos. O gerencialismo busca obscurecer a presença de diferenças fundamentais de interesse; aceitar a solução gerencial é sempre apresentada como uma situação em que todos ganham (MURPHY, 2008b, p. 154).
\end{abstract}

Para Murphy, o gerencialismo está promiscuamente disponível a qualquer ideologia que domina politicamente, seja neoliberal ou centralizada no governo (como na China); e como tal é pós-ideológico. Simultaneamente, ele argumenta que o gerencialismo provê uma ligação discursiva para a elite global. Enquanto o aceito, e de fato demonstro neste artigo o ponto de Murphy sobre despolitização e desconstrução, eu não o sigo inteiramente em termos de elites. Primeiro, eu gostaria de apoiar a possibilidade de que há interesses no que Escobar (2001, p. 146) chama de "capitalismo global" em NADAM. Segundo, um dos elementos interessantes no NADAM do trabalho do Banco Mundial sobre o Brasil, pelo menos como é formalizado em seus artigos para consumo global, é a exclusão de qualquer menção de trabalho daqueles que poderiam pertencer à parte do Brasil da elite global, seus acadêmicos das Escolas de Negócios (assim como sou). Terceiro, essa exclusão, com a implicação de que acadêmicos não são significativos suficiente para terem visões que precisam ser levadas em consideração em relação a processos nos quais eles são expertos em seu próprio país, nos diz mais da cumplicidade do NADAM em um fazer particular do Brasil. Este fazer não é o do lugar em si, mas de um lugar conhecido, representado e atuado em sentidos que significam seu status (para os significantes) como um lugar menor que pode ter coisas feitas para ele.

\section{Conhecendo o NADAM, conhecendo o Brasil}

Como um acadêmico baseado no Reino Unido, minha experiência e conhecimento sobre o Brasil são limitados. Ao levar o Brasil em consideração, sigo meu trabalho anterior (COOKE, 2004) que analisa as produções textuais e contas do Banco Mundial no país, analiso um 


\section{ADMINISTRAÇÃO E GESTÃO DE DESENVOLVIMENTO DO ATLÂNTICO NORTE NO GOVERNO DO BRASIL: UMA ANÁLISE HISTÓRICA DO BANCO MUNDIAL \\ Bill Cooke}

número pequeno de relatos de projetos do NADAM em um momento particular, o ano de 2009. O Brasil representado através de projetos ativos, páginas da web e documentos do Banco Mundial era um país onde a gestão pública era pobre e carente de desenvolvimento. Dos primeiros dez projetos listados (de 80i) (ver BANCO MUNDIAL, 2009ª) seisii eram, pelo menos em parte, explicitamente intervenções de gestão de desenvolvimento como fim no sentido de Brinkerhoff (2008). Isto é, seus objetivos incluem intenções específicas para aprimorar alguns aspectos da gestão do setor público como desenvolver metas em seu próprio direito. Todos os outros quatro projetosiii dos primeiro dez listados continham a palavra "gestão" no título, como "gestão de poluição", " gestão de recursos hídricos", "gestão ambiental" e "gestão de resíduo sólido" (BANCO MUNDIAL, 2009a).

Os seis projetos do NADAM envolvem empréstimos do Banco Mundial de US\$ 686,95 milhões de dólares no total. Como o Banco Mundial (2008b) ressaltou, o Brasil é incomum no que diz respeito ao Banco Mundial tê-lo feito empréstimos em níveis subnacionais de governo, como municipalidades. Isso em parte permitiu gastos mutuários adicionais e reais a esses projetos, então seu gasto real totaliza US\$ 1.771,88 milhões (BANCO MUNDIAL, 2009b; 2009c; 2009d; Banco Mundial, 2008a; 2008b; 2008c). Isso é uma parte da atividade e analisada retrospectivamente coloca em questão o problema comum da generalidade em termos de representatividade das relações do Brasil com

o Banco Mundial ao longo do tempo. O tempo de avaliação foi, entretanto, selecionado aleatoriamente; e a quantidade de dinheiro envolvido significa que eles são importantes, já que representam muito dinheiro gasto em atividades que incluem o NADAM.

Exemplificando o posicionamento do NADAM, o projeto do Distrito Federal é de grande importância simbólica dado que é onde a capital da nação, Brasília, está localizada. Gestão de desenvolvimento como meio foi atestado em seus objetivos: Os objetivos do projeto de desenvolvimento proposto (PDO) são:

... (i) aprimorar gestão e prestação de contas do setor público apoiando e expandindo as práticas de gestão baseadas em resultados e melhorando a supervisão fiduciária; (ii) aumentar o acesso, qualidade e eficiência dos serviços de educação, saúde e transporte público através da modernização do sistema educacional; da modernização, descentralização e integração de vários níveis do sistema de saúde; e fortalecendo a capacidade institucional e operacional do setor de transporte público (BANCO MUNDIAL, 2009c, p. 9).

Dos US\$ 400 milhões em despesa de projeto, US\$ 390 milhões eram para ser gastos no primeiro componente - fortalecer a gestão baseada em 


\section{ADMINISTRAÇÃO E GESTÃO DE DESENVOLVIMENTO DO ATLÂNTICO NORTE NO GOVERNO DO BRASIL: UMA ANÁLISE HISTÓRICA DO BANCO MUNDIAL \\ Bill Cooke}

resultados (RBM) no setor público. Isto era para ser gasto na "institucionalização do RBM em definição de políticas e administração pública", o qual "além de fortalecer a supervisão fiduciária, terá um impacto positivo na eficiência e eficácia dos gastos do governo, incluindo os três setores alvo". Dessa forma, isso contribuirá para:

Modernizar o sistema educacional objetivando a melhoria da qualidade, da eficiência e da equidade da educação básica. Essas reformas serão alcançadas através da adoção do modelo de Gestão Compartilhada, o qual inclui estratégias de resultados baseados no desempenho e incentivos escolares baseados em desempenho, além de apoiar a educação do sistema infantil, fundamental e médio. O projeto terá como alvo escolas com os indicadores educacionais mais baixos e aquelas localizadas em áreas de baixa-renda do DF...

Modernizar, descentralizar e integrar vários níveis do sistema de saúde, objetivando um aumento no acesso, na qualidade e na eficiência. Esses objetivos serão alcançados através do estabelecimento das práticas do RBM no setor, do desenvolvimento do sistema de informação gerencial e clínico e do Cartão de Saúde; da extensão do PHC (estabelecendo 127 equipes de Saúde Familiar em Regiões Administrativas) a fim de diminuir o fluxo nos hospitais; e do modelo experimental de gestão do Hospital Santa Maria pelo OS, o qual poderia ser expandido para outros hospitais...

Modernizar e aprimorar a gestão e a capacidade do SET e do DFTRANS a fim de permiti-los planejar, gerir, e supervisionar os serviços de transporte público mais eficaz e eficientemente e, consequentemente, melhorar o acesso e a qualidade. Isso incluirá, entre outras práticas, o estabelecimento do Centro de Controle Operacional 17 (CCO), o aumento da capacidade e a melhoria no sistema de transporte (o estabelecimento do $\mathrm{CCO}$ não envolve construção) (BANCO MUNDIAL, 2009c p. 16).

As abreviações são deliberadamente deixadas sem explicação, como aparecem no material original, justamente para mostrar como o documento encobre significados para leitores de Língua Inglesa e sem levar em conta a maioria da população falante do Português do Distrito Federal. O restante do fundo do projeto - 'somente' \$10 milhões - era para: 


\title{
ADMINISTRAÇÃO E GESTÃO DE DESENVOLVIMENTO DO ATLÂNTICO NORTE NO GOVERNO DO BRASIL: UMA ANÁLISE HISTÓRICA DO BANCO MUNDIAL \\ Bill Cooke
}

\begin{abstract}
Aumentar a Capacidade do Setor Público (US\$ 10 milhões). Este item financiará a assistência e o treinamento financeiro técnico para apoiar a realização das metas de desempenho estabelecidas no Componente 1. Atividades de assistência técnica específica estão incluídas para apoiar a implementação da gestão com base em resultados na GDF, particularmente nos setores alvos. Recursos estão incluídos para treinamento em planejamento estratégico, definição de indicadores (para o primeiro- e segundo- níveis RA), e M\&E para a equipe do SEPLAG e os Secretariados de Educação, Saúde, Transporte e DFTRANS. Como é complexo avaliar o progresso e desenhar lições para melhorias já em andamento, o Projeto aloca os recursos TA a fim de causar uma avaliação do impacto do programa de Gestão de Modernização, a ser finalizado em 2011 (BANCO MUNDIAL, 2009c p. 17).
\end{abstract}

Mais uma vez as abreviações foram deliberadamente deixadas sem explicação. Neste documento de projeto é particularmente difícil discernir em que pontos os US\$ 400 milhões serão gastos, se serão em melhorias materiais dos serviços mais necessitados em termos de recurso e pessoal, por exemplo em treinamento e emprego de mais professores ou profissionais da saúde, ou se na gestão em si. Certamente, alguns dos resultados do projeto são descritos em termos de melhorias tangíveis (para usar um termo gerencialista) em se tratando de, por exemplo, melhorias significativas em mortalidade pré-natal ou em taxas de progressão escolar. Entretanto, qualquer que seja o equilíbrio de despesas, de um lado, entre pessoas e recursos nas prestações de serviços, e de outro, na "melhoria" gerencialista e sua consonância com a realidade, o texto documental do projeto não pode ser lido como algo que não seja uma intervenção com uma aberta intenção de melhoria de gestão como é objetivo do NADAM. Contudo, também é importante notar que os outros seis projetos em questão, apesar dos documentos fortalecerem o discurso do NADAM, não definem explicitamente se os gastos são em recursos ou pessoas (e.g. o projeto Pernambuco, Banco Mundial 2009b). Desse modo, eu agora amplio meu foco para os seis projetos mencionados anteriormente, na tentativa de identificar declarações, temas, tropos, presenças e ausências comuns de acordo com a abordagem analítica em Cooke (2004).

\section{Gerencialismo Suplicante e Merecedor}

Perpassar pelos seis projetos do NADAM foi uma necessidade evidente do Banco Mundial para expressar o merecimento moral dos suplicantes atores Brasileiros. Isto apesar do fato de a contribuição financeira do Brasil para esses projetos ser mais substancial do que as do 


\section{ADMINISTRAÇÃO E GESTÃO DE DESENVOLVIMENTO DO ATLÂNTICO NORTE NO GOVERNO DO BRASIL: UMA ANÁLISE HISTÓRICA DO BANCO MUNDIAL \\ Bill Cooke}

Banco, o qual claramente está só emprestando dinheiro. Esta ideia surge em relatos narrativos de três maneiras. O status do suplicante (aos olhos do Banco), primeiramente, está implícito na revelação do detalhe íntimo do governo local Brasileiro em relação ao olhar mundial, via a apresentação ' $w w w$ ' dos hipercríticos meta-comentários em Língua Inglesa nos documentos do projeto, o qual posso citar a partir de minha casa em Manchester, Inglaterra. Segundo, há o uso, em Inglês, de descrições vivas, padronizadoras e simpatizantes dos atores Brasileiros, por exemplo (minha ênfase adicionada):

O mutuário tem completa propriedade do projeto e tem trabalhado diligentemente com 9 municipalidades para identificar as áreas principais para o investimento (BANCO MUNDIAL, 2009d, p. 14).

O Governador preparou um programa de desenvolvimento substancial e está projetando US\$ 3,3 bilhões de novos investimentos no período de 2007-2011 a fim de tirar Pernambuco da sua indisposição econômica e social (BANCO MUNDIAL, 2009b, p. 5).

Devido à complexidade do desenvolvimento e implantação do RHCN, MOH persistentemente apoiou a ajuda do Banco Mundial com o programa QUALISUSREDE (BANCO MUNDIAL, 2008a, p. 7).

Terceiro é a identificação da existência de um compromisso forte com a intervenção gerencialista:

Tido como um todo, o primeiro ano de governo do Governador Arruda [do Distrito Federal] produziu reformas importantes e expansão de capacidade. Os resultados de sua administração, juntamente com os programas de fortalecimento estrutural e institucional projetados para seu governo, amplamente justificam esta operação proposta. O projeto será implantado na capital do país, uma entidade de alto nível com espaço fiscal e um Governador reformista que é um forte agente do modelo Choque de Gestão (BANCO MUNDIAL, 2009b p. 13).

Como modelo, o "Choque de Gestão" de Minas Gerais chamou a atenção do GOP [Governo de Pernambuco] e outros governos Brasileiros subnacionais para a necessidade e para os potenciais benefícios em direcionar problemas administrativos básicos na administração pública estatal, e para avocar a gestão com base em 


\section{ADMINISTRAÇÃO E GESTÃO DE DESENVOLVIMENTO DO ATLÂNTICO NORTE NO GOVERNO DO BRASIL: UMA ANÁLISE HISTÓRICA DO BANCO MUNDIAL \\ Bill Cooke}

resultados como um meio de melhorar o desempenho e os resultados (BANCO MUNDIAL, 2009b, p. 13).

\section{Gerindo a mudança democrática}

Em dois dos seis projetos, a constante legitimidade política da democracia representativa foi identificada como um "risco"; isto é, a eleição de diferentes políticos representará uma ameaça ao projeto. Em um país onde eleição funciona normalmente, como é o caso do Brasil, identificar mudanças democráticas como "risco" é revelador. Nenhuma das abordagens gerenciais que devem ser empregadas para lidar com a mudança democrática - por exemplo, a implantação de projetos em estágios, pontos de rupturas, cláusula opt-out (cláusula de isenção) - são evidentes. E claro, o questionamento maior é porque esta eventualidade não foi explicitamente direcionada nos outros quatro projetos, dado que a duração foi além do mandato de qualquer político patrocinador eleito.

Nos dois projetos em questão, "participação" em democracia extrarepresentativa, no sentido de desenvolvimento participativo (COOKE; KOTHARI, 2001), e gerencialismo público per se, é proposta como resposta populista ao "risco" da democracia. Para o projeto Santa Maria, o qual faz parte de uma estratégia do NADAM mais ampla para cinco municipalidades, o risco e a resposta são descritos como:

Risco: eleições municipais podem eleger novas autoridades que não apoiam o projeto... (Banco Mundial, 2008b, p. 20).

Medida de Mitigação de Risco: Dado que o projeto irá representar o grosso dos investimentos municipais nos próximos 5 anos, a equipe Banco terá que manter uma comunicação aberta e ser receptiva às prioridades dos prefeitos eleitos. Dado que o projeto responde ao PPA [Plano Pluri-Anual], o qual reflete a demanda dos cidadãos, nenhuma mudança maior em investimentos prioritários é esperada (BANCO MUNDIAL, 2008b, p. 20).

Não há aqui espaço para descarregar o conjunto de preocupações críticas contidas nesses pequenos parágrafos. Contudo, primeiro, outra maneira de enquadrar o parágrafo é dizer que o projeto é deliberadamente designado para evitar responsabilidade e mudança democrática, apesar do seu foco no domínio público e seus gastos do dinheiro público. Ao invés de o projeto ser sujeito às vontades democráticas do povo através dos prefeitos eleitos, o povo e os prefeitos devem ser sujeitos ao projeto. Segundo, embora os processos participativos do PPA possam ter sido notáveis, a declaração de que eles representam as demandas dos cidadãos 


\section{ADMINISTRAÇÃO E GESTÃO DE DESENVOLVIMENTO DO ATLÂNTICO NORTE NO GOVERNO DO BRASIL: UMA ANÁLISE HISTÓRICA DO BANCO MUNDIAL \\ Bill Cooke}

que serão opostas às mudanças eleitorais implicam que sua legitimidade é pelo menos equivalente àquela democracia representativa institucionalizada. Enquanto há ambiguidade na escrita, parece que 36.000 pessoas estiveram envolvidas no processo participativo do PPA (BANCO MUNDIAL, 2008b, p. 24). Isso é, entretanto, de uma população de 259.000 (BANCO MUNDIAL, 2008b, p. 5). Além disso, o PPA e o projeto confundem-se, e enquanto generalidades e detalhes de um complexo projeto documental do Banco Mundial forem escritos em uma linguagem dialetal do próprio Banco Mundial em um Inglês altamente técnico, saturado com abreviações, e não forem analisados segundo o processo participativo do PPA, este não será indicado. Ainda, como o documento do projeto mesmo afirma, ele "representou o grosso dos investimentos municipais para os próximos 5 anos".

No projeto do Distrito Federal, há muitas questões discursivas e operacionais em torno do Governador Arruda, que é tido como positivoiv. $\mathrm{O}$ "risco" e a resposta às mudanças democráticas são como seguem:

Uma nova administração deve ser eleita em 2010 que deverá mudar a trajetória do movimento de reforma. Eleições para Governador do DF estão agendadas para Outubro de 2010, em um momento no qual as atividades do projeto já estarão a caminho. Se uma administração menos propensa às reformas ganhar a eleição, o progresso deverá ser lento. Entretanto, já que é esperado que as reformas continuem a produzir resultados positivos para o DF, e o Brasil e o DF continuem experimentando uma economia crescente, se outros estados (Minas Gerais e Ceará) continuarem a alcançar bons resultados com a reforma gerencial do setor público, é pouco provável que um novo governo no DF radicalmente mude de direção (BANCO MUNDIAL, 2009c, p. 27).

Não cabe a um acadêmico Inglês julgar as políticas do Governador Arruda. Contudo, é de extrema importância afirmar que o Governador Arruda, como Governadores dos Estados Unidos, fazia política como representante do conservador Partido Democratas, antigamente denominado Partido da Frente Liberal. Essa coligação política é normal em democracia, mas também é significativa para o projeto, embora não seja o tipo de informação que apareça nos relatos do Banco Mundial. Além disso, enquanto o espaço não nos permite um entendimento mais abrangente, devemos, pelo menos, notar os truques discursivos desse pequeno parágrafo. Assim, há a idealização da reforma (como um "movimento de reforma"), sua naturalização (há uma "trajetória" fundamental); e a afirmação explícita de que qualquer alternativa se coloca no caminho do progresso. Deve ser notado particularmente, embora seja 


\section{ADMINISTRAÇÃO E GESTÃO DE DESENVOLVIMENTO DO ATLÂNTICO NORTE NO GOVERNO DO BRASIL: UMA ANÁLISE HISTÓRICA DO BANCO MUNDIAL \\ Bill Cooke}

declaração de reforma de gestão do setor público - e o documento é claro, particularmente em relação ao choque de gestão, que haverá constante apoio popular como há agora; e há a suposição de que será uma preocupação fundamental para os eleitores fazerem escolhas políticas. O Banco sabe melhor do que o eleitorado em quem deveria e em quem irá de fato votar.

A natureza essencial/idealista do gerencialismo em geral nos documentos do Banco Mundial é evidente através do tratamento inquestionável e sem referência do choque em si. Claramente, entre os pesquisadores Brasileiros e acadêmicos em administração pública, há diferentes posicionamentos em relação ao choque, aqueles que foram seus apoiadores e/ou trabalharam em sua implantação e aqueles que veem como ufanismo (isto é, muito prescritivo em termos gerenciais); e há outros que criticam os pressupostos corporativistas e alegam uma agenda corporativa (VASCONCELOS, 2006). Meu foco aqui não é fazer um julgamento "correto" da análise (e como pesquisador Inglês seria errado fazê-lo). Ao invés disso, é apontar que há debates em torno do choque entre os acadêmicos Brasileiros e que não são reconhecidos em nenhum dos relatos do Banco, apesar da substancial quantidade de dinheiro gasta neles.

Isto em parte aponta para o que deve ser chamado de "meta-silêncio" em se tratando do NADAM no Brasil. A ausência de qualquer voz especialista Brasileira em suas reformas gerenciais nos seis documentos dos projetos. Isto é, enquanto o trabalho dos acadêmicos e intelectuais Brasileiros em algumas das esferas técnicas tal como saúde e educação são citados (embora problematicamente) nenhum trabalho equivalente na gestão do setor público foi levado em consideração (e.g. BRESSERPEREIRA; SPINK, 2007, sétima edição; WAMPLER, 2007). Nem são as alternativas localmente dirigidas, nem os projetos mais baratos reconhecidos (ver SPINK, 2000). Um público Brasileiro se familiarizará com um tipo de fonte, conduzido mais ou menos ao mesmo tempo, como a publicação do projeto documental de Imasato et al. (2009) que revisou uma literatura que consultava:

Periódicos principais... como a Revista de Administração Pública (RAP), Revista de Administração de Empresas, Revista de Administração Contemporânea, Organizações e Sociedade, Revista do Serviço Público e Revista Eletrônica de Administração... a base de dados da Scientific Electronic Library Online (SciELO) (...) a qual junta um conjunto de periódicos Brasileiros reconhecidos em... ciências sociais e ciências sociais aplicadas (...). Todos os artigos publicados nos arquivos dos anais disponíveis no banco de dados da Associação Nacional de Pós-Graduação e Pesquisa em Administração... e no Centro Latinoamericano de 


\section{ADMINISTRAÇÃO E GESTÃO DE DESENVOLVIMENTO DO ATLÂNTICO NORTE NO GOVERNO DO BRASIL: UMA ANÁLISE HISTÓRICA DO BANCO MUNDIAL \\ Bill Cooke}

Administracion para el Desarrollo... (IMASATO et al., 2009, p. 5).

Este não é o único silêncio. Apesar das alegações de aprendizagem organizacional contida nos relatos, e amplos discursos oficiais do Banco Mundial (ver COOKE, 2004), há uma completa e geral ignorância da história das intervenções de gestão do desenvolvimento do Banco Mundial no Brasil ao longo do tempo, o qual retomo abaixo (classicamente, em relação ao Banco Mundial sob ditadura militar ver SKIDMORE, 1988). Não é claro se o silêncio é de conhecimento associado com o local particular do Brasil e/ou se é também disciplinador, no qual nenhuma literatura Brasileira, Norte Americana ou Europeia em gestão crítica ou em outra área se detenha. Isso, em parte, afirma até que ponto as práticas e discursos de gestão do Banco Mundial possam ter um status naturalizado e indispensável.

\section{Conclusões}

Como tenho ressaltado, há versões Brasileiras autônomas de gestão do desenvolvimento, assim como há em outras partes do mundo. Entretanto, dizer que o NADAM não é completamente hegemônico, em espaço e em ação organizada, não é aceitar que ele não procura constantemente expandir sua variedade hegemônica. Há evidência, por exemplo, que técnicas e discursos radicais, participativos e localmente situados são frequentemente apropriados pelo NADAM (ver COOKE; KOTHARI, 2001) e minha análise acima confirma isso. Desse modo, o inventor da Avaliação Rural Participativa (ARP) e líder do Desenvolvimento Participativo do Atlântico Norte, Robert Chambers, pode retrospectivamente colonizar a obra de Paulo Freire em sua tradição. Então, uma forma de produção de conhecimento cessa ao tornar-se 'marginal' somente quando é colonizado pelo Atlântico Norte. Da mesma forma, há a intrigante ausência das significativas pesquisas sobre administração pública da academia Brasileira no projeto do Banco e de discursos mais amplos. Parece que não importa o quão erudito ou acadêmico a obra é pelo "objetivo" das medidas internacionais da academia, se até seus autores estão nas escolas 'triplamente creditadas', alguns lugares marginais ainda permanecem marginais (ver também ROSA; ALVES, 2011). Para o Banco Mundial reconhecê-los diferentemente, ele teria que reconhecer que há versões alternativas aos seus processos e aos resultados que acredita desejável em se tratando de desenvolvimento. Isso é verdade até mesmo dentro dos limites das comunidades acadêmicas nas áreas de gestão e das escolas de negócios no Brasil. E para haver esse reconhecimento, isso desafiaria o Banco Mundial e o direito assumido do NADAM de continuar a experimentar a (re)invenção do Brasil. 


\section{ADMINISTRAÇÃO E GESTÃO DE DESENVOLVIMENTO DO ATLÂNTICO NORTE NO GOVERNO DO BRASIL: UMA ANÁLISE HISTÓRICA DO BANCO MUNDIAL \\ Bill Cooke}

Este artigo tratou da Gestão de Desenvolvimento do Atlântico Norte, uma forma de gestão internacional no sentido básico das próprias palavras, mas ostensivamente dividido, por exemplo em se tratando de ideias e instituições, da GI como disciplina e discurso (ver MURPHY, 2008). Entretanto, GI e NADAM não devem ser vistos como isolados um do outro; de fato a questão de ambos é para quais finalidades servem sua ignorância mútua aparente.

Não menos importante, pode-se argumentar que cada um de fato precisa do outro, mas também precisa que o outro não seja reconhecido. GI precisa do NADAM através de suas instituições para de fato criar/sustentar um terreno no qual as corporações, que são sua preocupação primeira, possam operar, enquanto ao mesmo tempo se livram da responsabilidade gerencial pelas condições que elas mantêm e reproduzem, por exemplo em relação à pobreza e aos danos ambientais. Isso, em parte, fornece ao NADAM um Outro, algo que não é e não foi reconhecido inteiramente e que pode desafiar as hegemonias disciplinares da economia e antropologia nas práticas de desenvolvimento (internacional). De acordo com os níveis das ideias e práticas diárias, esta separação não ocorre inteiramente, e há, e sempre houve desde o começo do desenvolvimento no pós-1945, uma troca de ideias entre os dois tipos de disciplina (COOKE, 2003). No entanto, essa divisão significa que nenhum deles jamais deixa de ser responsabilizado em termos do seu irmão gêmeo secreto.

\section{Referências}

BLOOMFIELD, B., and T. VURDUBAKIS. Re-Presenting Technology: It Consultancy Reports as Textual Reality Constructions. Sociology, v. 28, n. 2, p. 455-477, 1994.

BRESSER-PEREIRA, L.C.; SPINK, P. Reforma do Estado e administração pública gerencial. 7· ed. Rio de Janeiro: Editora FGV, 2007.

BRINKERHOFF, D. W. The State and International Development Management: Shifting Tides, Changing Boundaries, and Future Directions. Public Administration Review, v. 68, n. 6, p. 985-1001, 2008.

CHAMBERS, R. "PRA, PLA and Pluralism: Practice and Theory." In: REASON, P.; H. BRADBURY (ed) The Sage handbook of action research. London: Sage, 2008.

COOKE, B. Participation, 'process' and management: lessons for development in the history of organization development. Journal of International Development, v. 10, p. 35-54, 1998. 
A new continuity with colonial administration: participation in development management. Third World Quarterly, v. 24, n.1, p. 47-61, 2003. 603-29, 2004.

The management of the (Third) World. Organization, v. 11, n. 5, p.

COOKE, B.; FARIA, A. Development, management and North Atlantic imperialism: for Eduardo Ibarra Colado. Cad. EBAPE.BR, v.11, n. 2, p. IXV, 2013.

COOKE, B.; KOTHARI, U. Participation: The New Tyranny? London: Zed, 2001.

COOKE, B. The Managing of the (Third) World, Organization v. 11, n. 5, p. 603-629, 2004.

A New Continuity with Colonial Administration: Participation in Development Management, Third World Quarterly, v. 24, n. 1, p. 47 -61, 2004.

DAR, S.; COOKE, B (ed). The New Development Management:

Critiquing the Dual Modernization. London: Zed Books, 2008.

DWIVEDI, O. P.; NEF, J. Crisis and continuities in development theory and administration: First and Third World perspectives. Public Administration and Development, v. 2, n. 1, p. 59 -77, 1982.

ESCOBAR, E. Power and Visibility: Development and the Invention and Management of the Third World. Cultural Anthropology, v. 3, n. 4, p. 428-443, 1988.

GRAHAM, L. S. Civil Service Reform in Brazil: Principles Versus Practice. Austin: University of Texas Press, 1968.

IMASATO, T.; MATOS MARTINS, P. E.; PENNA PIERANTI, O. Administrative Reforms and Global Managerialism: A Critical Analysis of Three Brazilian Sub-National State Reforms. Typescript under review, 2009.

HONEY, J. Towards Strategies for Public Administration Development in Latin America. Sryacuse: Syracuse University Press, 1968. 
LOBE, J. Learn from Cuba says World Bank. 2001. Disponível em: http://www.twnside.org.sg/title/learn.htm. Acesso em: 14 maio.2009.

MIGNOLO, W. D. The Idea of Latin America. Oxford: Blackwell Publishing, 2005.

MOTTA, P.R. ; SCHMITT, V. Administração para o desenvolvimento: a ideia e a renovação. Cad EBAPE.BR, v.11, n.2, p. 197-206, 2013.

MURPHY, J. “The Rise of the Global Managers.” In: DAR, S; COOKE, B. (ED)The New Development Management: Critiquing the Dual Modernization. London: Zed Books, 2008a.

MURPHY, J. The World Bank and Global Managerialism. London: Routledge, 2008b.

NKOMO, S. The Seductive Power of Academic Journal Rankings: Challenges of Searching for the Otherwise. Academy of Management Learning and Education, v. 8, n. 1, p. $106-112,2009$.

PECI, A. Taylorism in the Socialism that Really Existed. Organization, v. 16, n. 2, p. 289-301,2009.

PENDER, J. "Empowering the Poorest ? The World Bank and Voices of the Poor." In: CHANDLER, D (ed). Rethinking Human Rights: Critical Approaches to International Politics. London:Palgrave MacMillan, 2000.

ROSA, A.; ALVES, M. Pode o conhecimento em gestão e organização falar português? Revista de Administração de Empresas, v. 51, n.3, p. 255-264, 2011.

SKIDMORE, T. The Politics of Military Rule in Brazil. New York: Oxford University Press, 1988.

SPINK, P. The Rights Approach to Local Public Management: experiences from Brazil. RAE - Revista de Administração de Empresas, v. 40, n. 3, p. 45-65, 2000.

THRIFT, N. Knowing Capitalism. London: Sage, 2005.

THOMAS, A. What is Development Management? Journal of International Development, v. 8, n. 1, p. 95-110, 1996. 
Policy Arena: Development Management - Values and

Partnerships. Journal of International Development, v. 19, n. 3, p. 383388, 2007.

THURBER, C. E.; LAWRENCE, S G. (eds.) Development Administration in Latin America. Durham NC: Duke University Press, 1973.

TURNER, M. M.; HULME, D. Governance and Development: Making the State Work. London: Palgrave MacMillan, 1997.

VASCONCELOS, F. Empresas pagaram instituto para desenvolver reforma. Folha de São Paulo, August 13, 29. In IMASATO, T., P. E. MATOS MARTINS; PENNA PIERANTI, O. Administrative Reforms and Global Managerialism: A Critical Analysis of Three Brazilian SubNational State Reforms. Typescript under review, 2009.

WAMPLER, B. Participatory Budgeting in Brazil Contestation, Cooperation, and Accountability. University Park, PA: Penn State University Press, 2007.

WONG-MINGJI, D.; MIR, A. How International is IM? In: PRASAD, P.; A. MILLS; M. ELMES; PRASAD, A. (Ed). Managing the Organizational Melting Pot. Thousand Oaks: Sage, 1977.

WORLD BANK. Facing Up to New Challenges in the Way We Work Applying the Principles of the CDF, Disponível em: http://www.worldbank.org/cdf/story4.htm, Acesso em: 2 out.2001. In: COOKE, B. 2004. A New Continuity with Colonial Administration: Participation in Development Management, Third World Quarterly, v. 24, n. 1, p. $47-61,2001$.

Documents \& Reports. Project Appraisal Document on a Proposed Loan in the Amount of US \$235.0 Million to The Federative Republic of Brazil for a Health Network Formation and Quality Improvement Project (Qualisus-Rede) in Support of the First Phase of The Health Network Formation and Quality Improvement Program, December 17. 2008a.

Documents \& Reports. Project Appraisal Document on A Proposed Loan in the Amount of US\$13.95 Million to the Municipality of Santa Maria with the Guarantee of The Federative Republic of Brazil for an Integrated Municipal Infrastructure Project in Support of the Fourth Phase of the US\$66 Million Rio Grande do Sul Integrated Municipal Development Program (PDMI). November 26, 2008b. 
Documents \& Reports. Project Appraisal Document on a Proposed Loan in the Amount of US\$120 Million to The State of Acre with the Guarantee of The Federal Republic of Brazil for an Acre Social and Economic Inclusion and Sustainable Development Project (PROACRE) November 20, 2008c.

Documents \& Reports. Project Appraisal Document on a Proposed Loan in The Amount of US\$8.5 Million to The Republic Of Colombia for a Strengthening Public Information, Monitoring and Evaluation For Results Management Project Under The Statcap (Horizontal Adaptable Program Lending) Program. November 1, 2008d.

. Brazil: List of Active Projects. 2009a. Disponível em:

http:/ / web.worldbank.org/external/ default/ main?menuPK=322374\&pa gePK=141143\&piPK=141103\&theSitePK=322341. Acesso em: 01 maio. 2009 .

Documents \& Reports. Project Appraisal Document on a Proposed Loan in the Amount of US\$154.00 million to the State of Pernambuco with the Guarantee of the Federative Republic of Brazil for the Pernambuco Education Results and Accountability Project. March 11, $2009 b$.

Documents \& Reports. Project Appraisal Document on a Proposed Loan in The Amount of US\$130 million to the Federal District with the Guarantee of the Federative Republic of Brazil for A Federal District Multisector Public Management Project. February 20, 2009c.

Documents \& Reports. Project Appraisal Document on a Proposed Loan in the the Amount of Us $\$ 46$ Million to The State of Ceará With a Guarantee from The Federative Republic of Brazil for A Ceará Regional Economic Development Project (Cidades do Ceará - Cariri Central). January 16, 2009d.

Colombia Active Projects. Disponível em:

http:/ / web.worldbank.org/external/ default/ main?menuPK=324992\&pa gePK=141143\&piPK=141103\&theSitePK=324946. Acesso em: 14 maio. 2009,2009 e.

About Us: Challenge. Disponível em:

http:/ /go.worldbank.org/DM4A38OWJ0. Acesso em: 14 maio. 2009, $2009 f$. 


\section{ADMINISTRAÇÃO E GESTÃO DE DESENVOLVIMENTO DO ATLÂNTICO NORTE NO GOVERNO DO BRASIL: UMA ANÁLISE HISTÓRICA DO BANCO MUNDIAL \\ Bill Cooke}

Latin America and the Caribbean Regional Brief. Disponível em:

http:/ / go.worldbank.org/3TIKEV9IQ0. Acesso em: 14 maio. 2009. 2009g.

Bolivia Country Assistance Strategy Interim Note. Disponível em: http://go.worldbank.org/DXE8WC67P0. Acesso em: 14 maio. 2009. 2009h.

Latin America and Carribean. Disponível em:

http:/ /go.worldbank.org/F7T4DTVE20. Acesso em: 14 maio. 2009. 2009i.

\footnotetext{
' Não está claro se há mais de 79 projetos listados online ou se somente os 79 primeiros são listados. Variações entre as versões html e xls da lista totalizam 79, mas listam diferentes projetos com pequenas diferenças de data, como sugere a segunda hipótese.

ii Os seis projetos são: P106208 Prestação de contas e Resultados da Educação de Pernambuco (Banco Mundial 2009b); P107843 Projeto de Gestão Multissetorial do Distrito Federal Brasileiro (Banco Mundial 2009c); P099369 Desenvolvimento Econômico Regional do Ceará: Cidades do Ceará (Banco Mundial 2009d); P088716 Projeto de Melhoria de Formação e Qualidade do Sistema Brasileiro de Saúde QUALISUS-REDE (Banco Mundial 2008a); P11513 Programa Integrado de Desenvolvimento Municipal de Santa Maria - RS (Banco Mundial 2008b; trata-se de um componente de uma intervenção mais ampla em 5 municipalidades no sul do Rio Grande do Sul); e P107416 Projeto de Desenvolvimento Sustentável e Inclusão Econômica e Social do Acre - PROACRE (BANCO MUNDIAL, 2008c).

iii Identificação de projeto: P095205; P105389; P102818; P110481 (BANCO MUNDIAL, 2009a).

iv Por exemplo "A ... Administração Arruda lançou uma significativa reforma setorial pública logo após assumir o cargo"; "O Governador... Arruda... lançou um programa de reforma ambicioso concentrado no conceito RBM]"; "A administração Arruda lançou um programa ambicioso e abrangente a fim de melhorar os serviços de mobilidade e transporte público" (BANCO MUNDIAL, 2009c 1, 9, 45).
} 